\title{
Coping with and addressing the risks of children TV and online devices usage.
}

\author{
$A$ review and proposal of guidelines for parents \\ Maria José Casañ. Universitat Politecnica de Catalunya. \\ Marc Alier. Universtiatt Politecnica de Catalunya.
}

\begin{abstract}
Children start to be heavy users of media and connected devices as young as 5 years old. This widespread change of habits, while it is regarded as an opportunity for enhanced learning and acquisition of digital literacy, also raises concerns about the impact that is having and may have in the near future of children's health, development and exposure to risks.

Parents have to cope with these concerns and address these risks as part of their duties. "Parental Mediation" is the management of the relation of children with media and online devices. Parental mediation as a form of socialization as parents influence their children's behaviors and attitudes related to technology.

This paper analyzes the risks and implications of the growing exposure of children to tech, goes through a number of studies on parental mediation, and proposes a set of guidelines for parental mediation.
\end{abstract}

\section{CCS CONCEPTS}

- Social and Professional Topics • Computing Education • Computing Literacy - Computing/Technology Policy $\bullet$ Privacy $\bullet$ Surveillance

\section{KEYWORDS}

ICT kids, media, social media, risks, parenting mediation, recommendations, decalogue

\section{Introduction}

In recent years Internet-connected devices have gained a ubiquitous presence in our homes and daily lives. Computers, Smartphones, Tablets, Smart-TV's, and Game consoles have become ever-present in most homes and pockets, changing the way we communicate, consume media and entertainment, get information and learn. And this is also true for children, teenagers even for toddlers.

The widespread adoption of new connected technologies is having a huge impact on our culture, habits, and values. Just recently the voices of concern about the downside of new media, social networks, and new online technologies have reached the mainstream. It may be a coincidence but these voices have started to raise up after the scandal of Cambridge Analytica using social profiles and targeted ads to influence the results of the Brexit and US 2016 elections.

Tristan Harris, a former lead user experience designer at Google, has raised the warning about how the user experience designers are trying - and succeeding- to influence our behavior using a huge bag of tricks[1]. All the aspects of user interfaces and recommendation engines are designed, tested and improved to maximize the goals set by management. Harvard professor Shoshana Zuboff [2] states that IT giants like Google, Facebook, and Microsoft are what she calls Surveillance Capitalists. These companies have found ways to predict and influence our behavior, and extract behavioral surplus. Even Roger McNamee, a former Mark Zuckerberg mentor, has blown the whistle about the catastrophic effects that the direction Facebook is taking may have on society [3].

All this concern is relative to the effects of new media and social networks on adult society. Now let us talk about kids.

\section{New information technologies and children}

\subsection{Kids, media and social media}

The study of the impact of new technologies in children is really difficult because the new technologies are changing as fast as children grow. At any point in time, we have toddlers, children, and teens interacting with one iteration of technologies. As they age the devices, connection speed, availability of contents and kinds of media and services evolve and change the scenario altogether. So we believe that it is really important to pay attention to trends because the situation is in continuous development.

In the 1970s the children in the US had on average their first contact with screens at the age of 4 years old [4]. Their access to media was limited to TV and Radio, plus books, comic-books newspapers, and magazines, all content was broadcasted and noninteractive.

Almost 50 years later we see a radical change of the situation. US children have access to digital devices with interactive contents on demand since they are just 4 months old. A report shows that in Canada children of 3 and 4 years old spend on average two hours a day in front of a display . Only $22 \%$ of these kids are exposed to screens an hour or less. The same report remarks that 5 years old kids spend more of two hours a day in front of a screen [5]. 
According to systematic review of European research [6], most research on children and digital media has focused on children aged 9 and above, while research on younger children and their use of digital technology is more scarce and has only recently begun to expand.

In a study made in the United Kingdom in 2012 in kids aged 0 to 4 reveals that $27 \%$ use a computer of some kind and that $23 \%$ uses the Internet [7]. The main activity that kids perform is playing online games $(74 \%)$ and the most visited site is Cbeebies (61\%) (https://global.cbeebies.com/). According to the website, CBeebies is a site where we can find contents that allow "to have fun and learn at the same time"[5].

In the past decade, the amount of time that British children spend online has more than doubled: in 2005, 8 to 15 -year-olds went online 6.2 hours per week; in 2015 , the average was 15 hours. There is also a shift in the kind of devices kids use: in $2014,47 \%$ of kids of ages 3 to7 years old used tablets with internet access; in 2015 , this usage rose to $61 \%$. Some media uses are substituted over time for others, however, the hours spent by children per week have increased for both television (a little) and the internet (a lot) [8].

\subsection{A necessity among teenagers}

Teenagers have always sought time and space apart from parents and adults. Adolescents must develop a strong knowledge of themselves, they need to be sure of who they are and what they want to become. It is also important that they develop a certain sense of intimacy, they need to acquire skills that are important to form, maintain and even conclude relationships with others that are meaningful to them [9].

Walker attributes the shift in sleep patterns on teenagers, getting the need to sleep way later than children and adults, to an inherent need for privacy from adults to be able to develop their own cultural space where they can experiment and mature [10].

According to Aranda et At. [11], teenagers perceive the consumption of TV as an activity related to the home's common spaces, with an offer of contents and timing determined by the interests of the grownups. However, they see the consumption of online media as an activity unregulated by their parents that fit more to their social, cultural and psychological needs. Valkenburg and Peter state that balanced psychosocial development depends on the quality of the development of identity, intimacy, and sexuality [12].

Some authors see the Internet and social networks or different messaging tools such as Whatsapp or Snapchat becoming a field of experimentation for teens, an opportunity to explore their identity and intimacy without the supervision of traditional socialization agents such as parents, schools or institutes [9].

\section{Hopes and concerns regarding IT and children}

\subsection{Adoption, disruption, adaptation: caught in the cycle}

Every new technology adoption is fueled by some kind of promise of progress. The new technology is going to fix a problem or improve greatly an aspect of our lives. Then these technologies become so pervasive as to be an intrinsic part of our lives, causing a disruption in the order of things. Then we start to notice the problems that the new technology brings and we have to deal with it. Society adapts and the technology gets modifications and adjustments to create a new status quo, where society and technology stay in equilibrium.

As an example, let us consider transportation in the $\mathrm{XX}$ century. Cars provided a fast, cheap and clean way of transportation. At least cleaner than horses in a time where horse manure was present on every city street. Cars and trucks became widespread and society got disrupted. After the massive adoption of cars, we noticed the problems that came with them and slowly there were introduced traffic regulations, mandatory insurances, technology improvements for safety (tail lights and signals, seatbelts, anti-lock brakes, traction control, and airbags) and environmental evolutions of the technology (catalyzers, improvement of engine efficiency, unleaded fuel, etc.).

The promise fuels the adoption of technology, the unforeseen negative side effects fuels the process of adaptation.

Information technologies are no different from other technologies like the technologies of transportation.

But in the XXI century with computers, tablets, smartphones, and the internet, we are dealing with a special kind of innovation: one that accelerates at a pace that exceeds the pace of adaption. Just consider that the smartphone was introduced in mid-2008 (The iPhone was presented in early 2007, but it did not include Apps and an Appstore and had a small distribution restricted to the US and one carrier). The children who were starting primary school back then, are still in high school. They learned about this technology at the same time their teachers and parents did.

But a smartphone from 2008 cannot compare to the devices we carry today. These are loaded with broadband internet access, high definition video cameras, with streaming capabilities, filters that give you instant makeup and mouse ears and whiskers, or turn you into an animated emoji (emojis are also a recent innovation), augmented reality features and voice-activated assistants. We are continuously figuring out the features of our new technologies and their impact on our lives. These are the same technologies that our students and offspring use for learning, entertainment and communicate with their peers.

The cycle of technology adoption, disruption, and adaption has compressed to a point where several iterations happen at the same time.

This can lead researchers to get bogged off on issues caused by a current iteration of the technology while the next iteration fixes this issue altogether. An instance of this case is the frenzy of concerns raised about the influence of SMS in written language, especially among students. Freudenberg and Kristy were investigating the impact of SMS speak on the written word of English first language and English second language on high school learners [48].

The advent multi-touch keyboards with predictive correction and later voice snippets on messaging apps turned this into a non- 
issue and SMS related abbreviations are something of no consequence.

\subsection{The promise of innovation}

Information technologies have been introduced to children since the early 1970s. Bill Gates and Paul Allen had access to a computer in their school. Seymour Papert pioneered the research in using computers as educational tools convincing Steve Wozniak to use Apple II in educational projects. One of the authors of this paper worked in the early 9190s teaching to children the programming language created by Papert: LOGO.

Since then the use of IT for educational purposes has been well regarded in the eyes of parents, researchers, educators, and politicians.

In the XXI century, internet-connected computers and software became not only a tool for improving learning but something to be learned itself. This new scenario has important consequences in the curricular framework design: the need to adapt the curriculum of all the lessons and review them according to the new profiles of knowledge demanded by the information society, incorporating ICT and doing it.

A noteworthy example is Nicholas Negroponte's One Laptop Per Child (OPLC) initiative that aimed to create 100 \$ laptops to be used by children in developing countries. The laptops loaded with educational software and mesh network capabilities were aimed to be a complement to or a proxy to the work of teachers. The project had mixed results but spawned the industry of netbooks - cheap laptops - that today are used in schools worldwide [23].

The new online technologies came with the promise of innovation, bringing better ways to learn more aligned with the requirements of the information society.

\subsection{Concerns}

Despite the allure of the new internet connected devices, ever more portable, convenient and powerful, and its potential for learning, entertainment, and connection with peers, as with every new kind of technology, we find some issues that raise concern.

\subsubsection{Toddlers and younger children}

Toddlers, children aged 0 to 3, like screens and seem to learn quickly their way around touch interfaces. TV has been used as an "electronic babysitter" for decades, but recent evidence suggests that excessive media in infants and toddlers is correlated with observed "difficult" temperament [20-21] or self-regulation problems [22]. Population-based studies show associations between excessive TV viewing in early childhood and cognitive[15,17], language [13-14] and social/emotional delays.

Evidence suggests that toddlers need to explore the world that surrounds them and interact with other toddlers under the supervision of adults to be able to develop speech, motor functions, and socio-emotional abilities [18].

According to the American Academy of Pediatrics, children who are younger than 30 months old present a difficulty to learn from 3D representations projected in a 2D display. Due to what is considered an immature memory, and a short attention span, these children display limited ability to transfer what they see in $2 \mathrm{D}$ to $3 \mathrm{D}$ [19]. Most of the sources we have encountered warn that children under 18 months should not be exposed to screens of any kind. Before 2 years of age, children are still developing cognitive, language, sensorimotor, and social-emotional skills, which require hands-on exploration and social interaction with trusted caregivers for successful maturation.

Last but not least there is concern about a loss of sleep and sleep quality. Six to 12-month-olds who were exposed to screen in the evening hours showed significantly shorter night-time sleep duration than those who had no evening screen exposure [24].

\subsubsection{Children and teenagers}

As we have seen previously, children start to be heavy users of media and connected devices as young as 5 years old. This change in habits starts to raise concerns among parents and educators. Sociologists have identified a new generational change, with the advent of the Generation $\mathrm{Z}$ or iGen. This generational change arrives sooner than expected, followed by yet a new generation change starting with those born around 2010, coinciding when smartphones became mainstream [52].

The first concern is about the long term the impact of the exposure to media, new media, and social media contents. In the late 1960s, Gerbener introduced the "cultivation theory" stating that heavy consumption of industrialized mass-mediated storytelling, most clearly exemplified by television (TV) programming, "cultivated" a fearful attitude to the world, which had gradual but serious long-term negative consequences for its viewers' outlook and beliefs. Bandula's (1977-1994) "social cognitive theory of mass communication" highlights how media messages may influence viewers both in short and long terms. According to Bandula children and adolescents learn by imitating their role models, which include those on TV and video games, especially if the models are appealing or similar to children [2526].

A second concern is a possible impact on health. Studies have shown that exposure to alcohol or tobacco use or risky sexual behaviors in TV or movies is associated with initiation to these behaviors [27-30]. New studies suggest that digital and social media also induces this effects. Several studies show that adolescents frequently display on social media portrayals of risky health behaviors, such as alcohol and or illicit substance consumption, sexual behaviors, harmful behaviors, such as selfinjury or disordered eating, and display of risky activities like taking selfies on risky locations [31-35]. Evidence shows that viewers of this content are influenced to regard these behaviors as normative and desirable [36-38]. Social media combine the power of interpersonal persuasion with the reach of mass media. Fogg stated that this is "the most significant advance in persuasion since the radio was invented in the 1890s." [39].

The impact of trend creation and culture shaping of new media and social media is compounded by the effects of recommendation engines. In the first generations of new media (like youtube) and social media (like Facebook or Twitter) a user 
would receive in their feeds the contents generated by their "friends" or the channels they were subscribed to. But in the last 10 years, the content presented to the user is selected by recommendation algorithms. These algorithms are fueled by big data about the previous viewing of the user, their peers, and "cohorts" where she has been included, and select content to maximize parameters defined by the company who runs the gig. The impact on teenagers of these practices on social networks like Instagram compound the risks [1-2].

Studies show that excessive media use and media use can cause alterations in sleep patterns and obesity and cardiovascular risk. This has been observed starting in early childhood [49]. Heavy media use during preschool years is associated with small but significant higher Body Mass Index (BMI),75 increasing the chances greater weight gain later in childhood. The correlation between daily media consumption greater than 2 hours and obesity persists even after adjusting for children's psychosocial risk factors or behavioral problems.76 A recent study of 2-yearolds found that BMI increased for every weekly hour of media consumption.77 Studies of older children and teenagers confirm the correlation between media use and obesity.80 In a 1996 study of 5- to 10-year-olds, the odds of being overweight were 4.6 times greater for youth watching more than 5 hours of TV per day compared with those watching 0 to 2 hours [50].

Another concern is the risk of sleep patterns alterations. Increased duration of media exposure and the presence of a TV, computer, or mobile device in the bedroom in early childhood have been associated with fewer minutes of sleep per night [51]. Some suggested causes are later bedtimes after evening media use, violent content in the media or games, 92 and suppression of endogenous melatonin by blue light emitted from screens [41].

Studies of older children and teenagers have found that those who use more social media 95 or sleep with mobile devices in their room96,97 were at greater risk for sleep disturbances. This has been proven to be true even in adults, smartphone use in bed leads to great sleep latency, worse sleep quality, more sleep disturbance, and more daytime dysfunction [53].

Other risks we have encountered and have been documented by studies are the risk of low self-esteem [40], to be victims or perpetrators of cyberbullying [54-55] sexting or being groomed by an adult to participate in online or face to face sexual activities [42-43].

\subsubsection{Risk inequality}

While reviewing the literature we have encountered a compounding risk factor. Children and teenagers in families with low income, who belong in ethnical minorities or with a risk of exclusion, and single parents see their risks increased in study after study.

We see a new kind of digital divide, not one of access but one of quality. Studies show that poor families are more likely to have more connected devices that middle income and rich families. But usually, the devices used in poor families are smartphones or tablets, not connected computers. Smartphones are personal devices, and its use is more difficult to be mediated restricted by the parents.

In poor families and single-parent families, adults work longer hours or have a second or third job. In these cases, connected devices are the "digital nannies" increasing the risks [6].

The family has a very important impact on whether or how children use media. Children using media are at the same time exposed to potential exploitation of media marketing. Parents are not aware of this directly since they are also exposed to the same risks and effects themselves.

Research has shown TV viewing distracts parents from interactions [44] and play with their children [45]. Toddlers are vulnerable to watch inappropriate "background" content than older children [46]. Heavy use of mobile devices in parents is associated with fewer verbal and nonverbal interactions with children [47] and may be associated with more parent-child conflict [48].

\section{Coping with and addressing risks: Parental Mediation}

In the previous part, we established that the new media, social media, video games, and social networks have entered our homes and the lives of our children. These technologies come with the hope of improving our lives and new learning opportunities. We cannot ignore lightly the promises of these new technologies with the risk of missing out on key elements that shape the near future culture and workplace in our society. But there is also a set of risks these new technologies entail. As parents set the tone in terms of how media is used at home measured in terms of devices and other practices, they also have to cope with and address these risks as part of their duties as such.

\subsection{Parental Mediation definition and strategies}

The term "Parental Mediation" was first defined as the management of the relation between children and media [56] and can be extended today to the usage of online devices. Youn considers parental mediation as a form of parental socialization because parents, influence their children's behaviors and attitudes to become more competent technology users [58]. A successful parental mediation helps the development of children's media literacy which may mitigate and provide tools to deal with harmful media effects [56].

Livingstone and Helsper [56] created four widely-used mediation types specifically for the mediation of children's digital media usage: active and co-use mediations, technical restrictions, interaction restrictions, and monitoring.

The active mediation strategy is about sharing the media while the children are consuming it. This strategy is more active while using the internet than when watching TV. The parent is sitting near the children and talks to them about the activity they are engaging in.

The co-use strategy involves the parent using the device together with the child. Co-use also involves restrictions associated with the communication of personal information online, shopping online, completing forms, etc. since parents can 
explain and enforce such restrictions during co-use. A study performed in Belgium identified two types of co-use showing that parents behaved as "helpers" or as "buddies" [60]. "Helpers" guide their children to learn or to deal with problems of usage. "Buddies" share some media activities with their children purely for enjoyment [60].

The restriction strategies are usually divided into two different categories: technical restrictions and interaction restrictions. Technical restrictions make use of parental control software or router configuration that, for example, filter content and prevent access to some websites. This strategy can be used to enforce house rules like the amount of time online allowed or timetables, disconnecting the device or the Wifi connection. The interactionrestriction strategy is associated with the prohibition of contacting others unless under parent supervision (e.g., using email, chat, game playing).

The strategy of parental monitoring consists in checking the child's activities after or during the child's use of the internet, either covertly or overtly [56].

Despite taxonomies, according to Smahelova, there is no one parental meditation strategy but these strategies vary according to different situations [57]. Parents mediate between the media and children by setting rules and by the fact that their own media habits unconsciously affect those of their children [25].

The restriction strategies may be successful to reduce risks since they eliminate exposure. But it has its drawbacks. According to [8] parents who heavily restrict internet access tend to have children who experience reduced exposure to risk but fewer opportunities for learning and engagement. Outright bans of activities such as using social media or playing video games can have consequences for young people, who may feel cut off from their peers, or unable to access information and support. If children use media less and less deeply, they may not get the chance to explore the media possibilities or to develop skills needed to benefit from it in the present and in the future [8].

The focus solely on risk reduction can be a double edge weapon of choice. Risk reduction reduces the probability of encountering issues. But when issues are encountered, kids who have not developed digital literacy and coping strategies are more vulnerable to the effects of such issues and also feel powerless, which can also lead to psychological and social problems.

Most studies accessed and authors regard, discussion-based active mediation is more effective than other types of parental mediation in reducing negative media influence on children. When parents engage with media with their children, the children learn more $[8,59]$. However, active mediation is a more hands-on practice, as it requires parents to have some level of knowledge and understanding of media technology to initiate talks on mediarelated issues [64].

\subsection{Inequality of income and digital literacy, its effects on parental mediation.}

We have found in the literature a recurrent reference to how inequality of income and digital literacy of the parents translates to the kinds of strategies of parental mediation and its effectivity. Parents in lower-income families frequently invest disproportionate resources into digital media, making considerable sacrifices to purchase equipment that middle-class families take for granted. And they tend to use more restrictive than active mediation [8]. Parents with higher levels of digital literacy (regardless of income but correlated with educational levels) are more able to combine restrictive and active strategies to generate positive outcomes [8].

Studies demonstrate that the parent's confidence about their internet skills is positively associated with the extent to which they engage in monitoring and supervising their children's media use $[56,62]$.

Parent's self-efficacy plays an important role in the parental mediation strategy and its effectivity [60]. Graf et al. proposes training programs for parents to provide them with self-efficacy in new media technologies, to empower to make better and more effective mediation with their children [61].

\section{Conclusions and recommendations}

Every generation deals with the available technologies and the challenges these technologies entail. In the XXIst century, we are living under the "future shock" that Alvin Toffler [63] predicted in 1970. While we are barely adapted to a technology a new iteration of the technology comes along and gets into our hands. And this process is exponentially accelerated, propelled by Moore's law and other exponentiality of tech. We would not adopt these new technologies if they would not add something positive to our lives, or would not make sense in the way our everglobalizing society works.

All of us, citizens, educators, parents, and children need to learn new abilities and competencies to deal with these changes. The competencies must include managing our relationship to the new addictive by design technologies, protect our privacy and make the most of it.

It is of paramount importance that parents and educators to understand the advantages, opportunities, and risks of the new technologies that we incorporate in our homes, classrooms, pockets and we even wear.

After the revision of extensive relevant literature and studies, the authors now introduce a decalogue of recommendations for those in the role of parenting to mediate with some of the new technologies.

\subsection{Yet another decalogue of recommendations}

This decalogue has in mind parental mediation for children aged 2 to 12 years old. It takes into consideration the recommendations studied in the State of the Art. Some recommendations may make sense with teenagers, others should be revised and thought out in further work.

1. Carefully choose quality contents appropriate for the age of every child and coherent with the culture of the family.

a. The best way for a parent to know if something is appropriate for a child is to sample it beforehand 
and use her common sense. This however takes time and effort. As a proxy for this practice, parents should look for trusted reviews, guidelines, and recommendations of contents for every age. They also need to look for and understand and follow movie ratings and the PEGI index for videogames.

b. b. Children should not be able to download Apps, movies or access random websites without authorization. They should learn to ask if some content is appropriate or not for them. This practice helps with risk prevention and makes children aware that not all contents are equal in quality or are appropriate.

2. Set limits for the amount of time allowed for engaging with IT and monitor it. Parents should look for a balance between digital and analog activities.

a. Do not leave the TV on as "background noise" when TV time is over.

b. Be aware that online devices and TV have an addictive component embedded in their design. The more kids are exposed to screens the more she will ask for it

c. Protect sleep. Avoid the use of screens at least for an hour before bedtime. It can disrupt sleep patterns for a number of reasons. In particular, the blue light emitted by LED displays affects the circadian rhythm. This can be palliated for the parent's own sleep quality by setting up software that changes the color temperature of the display at noon. In any case, the hour(s) before bed should be used for cooldown activities like reading stories to children.

d. Avoid electronic devices while children are doing the homework. This affects their concentration. Multitasking is a toxic myth that is getting into the culture. An obvious exception would be when the electronic device is required specifically to do the homework.

3. Try to take advantage of media contents to engage and interact with the children and develop their creativity. Couse the media with them and talk to them about it. Diversify the kinds of contents that children are exposed. Children are as likely to binge-watching as adults.

4. 4. TV, video games, and online devices are not a digital nanny. Kids enjoy and learn more with contents and games when they engage with them with their parents and children adult interaction is present. This also helps parents to be connected with their children.

5. Teach and, most importantly, show by example to discriminate when is adequate to use online devices depending on the context and existing social rules.

a. Ban TV, smartphones and other devices during meals. !This applies especially to parents!. The authors are also guilty as charged and ashamed.

b. Reserve a specific room to store and charge computers, tablets, and smartphones.

c. Do not leave devices charging in the children's room.

6. Progressively explain and show to children what is digital identity, its implications for the present and future. As they start using social media and social networks help them understand the concepts of privacy, confidentiality, and intimacy, how to protect it and respect it for others.

a. Control and monitor the information children share online. Pictures and videos of themselves and other children are especially sensitive. Parents should self-monitor what they share about their children and to whom. (Clue: Facebook friends are not always your friends and what gets in the Facebook gets in the Facebook).

b. Children should not chat or engage online with strangers without parents approval or supervision. Talk to your kids, accordingly to their age, about the implications of this issue like you will about engaging with strangers on the street.

c. Read and understand the privacy policies of the apps sites and sites were your children interacts.

d. Learn and understand tools for security and privacy management on your devices and those your children use.

e. Know the tools of parental control. Use them sparingly.

f. Cyberbullying is an issue your children can be victims or perpetrators of. Talk to them about it.

g. Parents should aim to provide the children the trust and confidence to talk to them when they receive unsettling messages, pictures or other kinds of content.

h. Explain to children what are adds and marketing. Teach them to have an open mind and to practice skeptic inquiry about the messages they receive.

7. Keep spaces and moments free of technology in the home. The children's room and mealtime should be among them. Explain to the children why it is important.

8. Create with your children the guidelines for TV and online devices usage. When children are younger it needs to be something you come up and enforce, but as they grow is important and useful if the children get a say on it. Note that it may also include duties and limitations for parents.

9. Explain to other caretakers for the children, such as nannies and grandparents the guidelines that the family has chosen for TV and online devices usage. This one is extremely difficult.

10. 10. Do analogic offline stuff with your children. Playing games, going outdoors, doing sports and reading stories should be on the list. Note that sharing it online may spoil it

\section{It never ends}

The issues related to the introduction of new technologies in the home or the classroom are going to keep on appearing. As we write this paper new technologies not considered by the studies consulted and our approach, have made its way into the mainstream: smartwatches, voice assistants, augmented reality and virtual reality just to name a few.

While we are still developing and testing strategies to deal and cope with the technologies that have made their way into our lives, new technologies are waiting for us to be adopted. We can even hope, some of the new technologies to come will have 
embedded in their design the solution to problems that we face in the present. Just like predictive spellcheck enabled touch keyboards made all concerns about SMS spelling not relevant, we may come up with new technology approaches that help us to relate with technology and each other in better, safer and saner ways.

\section{REFERENCES}

[1] T Harris, 2016, How Technology Hijacks People's Minds-from a Magician and Google's Design $\quad$ Ethicist. Avaliable at http://www.tristanharris.com/2016/05/how-technology-hijacks-peoplesminds\%E2\%80\%8A-\%E2\%80\%8Afrom-a-magician-and-googles-design-ethicist/ (accessed on 30/6/2019)

[2] S Zuboff (2015). Big other: surveillance capitalism and the prospects of an information civilization. Journal of Information Technology, 30(1), 75-89.

[3] R McNamee, 2019, Zucked: waking up to the Facebook catastrophe. Penguin Press.

[4] L Yolanda, R Chassiakos, J Radesky, D Christakis, MA Moreno, C Cross (2016). Council on Communications and Media Pediatrics, 138 (5), 2016-2593.

[5] C L'Ecuyer, 2019, El uso de las tecnologías digitales en la primera infancia: entre eslóganes y recomendaciones pediátricas. Dosier Cerlarc. Lectura digital en la primera infancia.

[6] K Ólafsson, S Livingstone, \& L Haddon, 2013, Children's use of online technologies in Europe: A review of the European evidence database. London: EU Kids Online.

[7] Childwise, 2012, The Monitor Pre-school Report 2012: Key behaviour patterns among 0 to 4 year olds. Norwich.

[8] A Blum-Ross, \& S Livingstone, 2016, Families and screen time: Current advice and emerging research.

[9] G Roca (Coord.), 2015, Las nuevas tecnologías en niños y adolescentes. Guía para educar saludablemente en una sociedad digital. Barcelona: Hospital Sant Joan de Déu (ed).

[10] M Walker, 2017, Why we sleep: The new science of sleep and dreams. Penguin UK.

[11] D Aranda, M Roca, \& J Sánchez-Navarro, (2013). Televisión e internet. El significado de uso de la red en el consumo audiovisual de los adolescentes. Quaderns del CAC, 16 (39), 15-23.

[12] PM Valkenburg, \& J Peter (2011). Adolescents' online communication: An integra- ted model of its attraction, opportunities, and risks. Journal of Adolescent Health, 48, 121-127.

[13] FJ Zimmerman, DA Christakis, AN Meltzoff (2007). Associations between media viewing and language development in children under age 2 years. Journal Pediatr., 151(4), 364-368.

[14] H Duch, EM Fisher, I Ensari, et al. (2013). Association of screen time use and language development in Hispanic toddlers: a cross-sectional and longitudinal study. Clin Pediatr (Philadelphia), 52(9), 857-865.

[15] S Tomopoulos, BP Dreyer, S Berkule, AH Fierman, C Brockmeyer, AL Mendelsohn (2010). Infant media exposure and toddler development. Arch Pediatr Adolesc Med. 2010;164(12):1105-1111.

[16] ME Schmidt, M Rich, SL Rifas-Shiman, E Oken, EM Taveras, 2009. Television viewing in infancy and child cognition at 3 years of age in a US cohort. Pediatrics, 123(3). Available at: http://pediatrics.aappublications.org/content/123/3/e370pmid:19254972 (accessed on 30/6/2019)

[17] LY Lin, YJ Cherng, MH Yang, 2015, Effects of television exposure on developmental skills among young children. Infant Behav Dev. ,38,20-26.

[18] A Brown (2011). Council on Communications and Media. Media use by children younger than 2 years. Pediatrics. 128(5),1040-1045.

[19] R. Barr (2013). Memory constraints on infant learning from picture books, television, and touchscreens. Child Dev Perspect, 7(4), 205-210

[20] AL Thompson, LS Adair, ME Bentley (2013). Maternal characteristics and perception of temperament associated with infant TV exposure. Pediatrics, 131(2). Available at: http://pediatrics.aappublications.org/content/131/2/e390 (accessed on 30/6/2019)

[21]M Sugawara, S Matsumoto, H Murohashi, A Sakai, N Isshiki (2015). Trajectories of early television contact in Japan: relationship with preschoolers' externalizing problems. J. Child Media, 9(4):453-471.

[22] JS Radesky, M Silverstein, B Zuckerman, DA Christakis (2014). Infant selfregulation and early childhood media exposure. Pediatrics, 133(5). Available at: http://pediatrics.aappublications.org/content/133/5/e1172 (accessed on $31 / 6 / 2019)$

[23] N Negroponte, 1998, Beyond digital. Wired 6.12.

]24] N Vijakkhana, T Wilaisakditipakorn, K Ruedeekhajorn, C Pruksananonda, W Chonchaiya (2015). Evening media exposure reduces night-time sleep. Acta Paediatr, 104(3):306-312.
[25] B Macuh , A Raspor, M Sraka, \& A Kovačic, A. (2018). Media exposure and education of first to six grade children from slovenia-parent opinions. International Journal of Cognitive Research in Science, Engineering and Education, 6(3).

[26] D Romer, P Jamieson, A Bleakley, KH Jamieson, 2014, Cultivation Theory: Its history, current status and future directions. Willey \& Sons Inc.

[27] PP Gidwani, A Sobol, W DeJong, JM Perrin, SL Gortmaker (2002). Television viewing and initiation of smoking among youth. Pediatrics, 110(3):505-508.

[28] MA Dalton, ML Beach, AM Adachi-Mejia et al (2009). Early exposure to movie smoking predicts established smoking by older teens and young adults. Pediatrics, 123(4). Available at: http://pediatrics.aappublications.org/content/123/4/e551

[29] TN Robinson, HL Chen, JD Killen (1998). Television and music video exposure and risk of adolescent alcohol use. Pediatrics, 102(5).

[30] JD Klein, JD Brown, KW Childers,J Oliveri, C Porter, C Dykers (1993). Adolescents' risky behavior and mass media use. Pediatrics, 92(1):24-31.

[31] S Hinduja, JW Patchin (2008). Personal information of adolescents on the Internet: A quantitative content analysis of MySpace. J Adolesc, 31(1):125-146.

[32] MA Moreno, MR Parks, FJ Zimmerman, TE Brito, DA Christakis (2009). Display of health risk behaviors on MySpace by adolescents: prevalence and associations. Arch Pediatr Adolesc Med.,163(1),27-34.

[33] MA Moreno, M Parks, LP Richardson (2007). What are adolescents showing the world about their health risk behaviors on MySpace? MedGenMed., 9(4).

[34] JB McGee, M Begg (2008). What medical educators need to know about "Web 2.0". Med Teach., 30(2), 164-169.

[35] MA Moreno, A Ton, E Selkie, Y Evans (2016). Secret Society 123: understanding the language of self-harm on Instagram. J Adolesc Health., 58(1), 78-84.

[36] MA Moreno, LR Briner, A Williams, L Walker, DA Christakis (2009). Real use or "real cool": adolescents speak out about displayed alcohol references on social networking websites. J Adolesc Health., 45(4), 420-422.

[37] MA Moreno, R Kota, S Schoohs, JM Whitehill (2013). The Facebook influence model: a concept mapping approach. Cyberpsychol Behav Soc Netw., 16(7), 504-511.

[38] DM Litt, ML Stock (2011). Adolescent alcohol-related risk cognitions: the roles of social norms and social networking sites. Psychol Addict Behav., 25(4), 708713.

[39] BJ Fogg, 2008. Mass interpersonal persuasion: an early view of a new phenomenon.In Oinas Kukkonen H, Hasle P, Harjumaa M, Segerståhl K, Øhrstrøm P,eds. Persuasive Technology, Third International Conference, PERSUASIVE 2008, Oulu, Finland, fune 4-6, 2008, Proceedings. Berlin, Germany: Springer-Verlag Berlin Heidelberg, 23-34.

[40] N Martins, K Harrison (2012). Racial and gender differences in the relationship between children's television use and self-esteem a longitudinal panel study communication research. Communic Res., 39(3), 338-357.

[41] R Salti, R Tarquini, S Stagi et al (2006). Age-dependent association of exposure to television screen with children's urinary melatonin excretion? Neuroendocrinol Lett., 27(1-2), 73-80.

[42] CT Halpern, CE Kaestle, DD Hallfors (2007). Perceived physical maturity, age of romantic partner, and adolescent risk behavior. Prev Sci.,8(1), 1-10.

[43] J Neemann, J Hubbard, AS Masten (1995). The changing importance of romantic relationship involvement to competence from late childhood to late adolescence. Dev Psychopathol, 7(4), 727-750.

[44] HL Kirkorian, TA Pempek, LA Murphy, ME Schmidt, DR Anderson (2009). The impact of background television on parent-child interaction. Child Dev., 80(5), 1350-1359.

[45] ME Schmidt, TA Pempek, HL Kirkorian, AF Lund, DR Anderson (2008). The effects of background television on the toy play behavior of very young children. Child Dev. , 79(4), 1137-1151.

[46] J Radesky, AL Miller, KL Rosenblum, D Appugliese, N Kaciroti N, JC Lumeng (2015). Maternal mobile device use during a structured parent-child interaction task. Acad Pediatr., 15(2), 238-244.

[47] JS Radesky, CJ Kistin, B Zuckerman et al. (2014). Patterns of mobile device use by caregivers and children during meals in fast food restaurants. Pediatrics, 133(4). Available at: http://pediatrics.aappublications.org/content/133/4/e843pmid:24616357 (accesses on 30/6/2019)

[48] Y Hård Segerstad, 2005, Language in SMS-a socio-linguistic view. The inside text, 33-51.

[49] S Bel-Serrat, T Mouratidou, AM Santaliestra-Pasías et al (2013). IDEFICS consortium. Clustering of multiple lifestyle behaviours and its association to cardiovascular risk factors in children: the IDEFICS study. Eur J Clin Nutr., 67(8), 848-854.

[50] SL Gortmaker, A Must, AM Sobol, K Peterson, GA Colditz, WH Dietz (1996). Television viewing as a cause of increasing obesity among children in the United States, 1986-1990. Arch Pediatr Adolesc Med., 150(4), 356-362.

[51] EM Cespedes, MW Gillman, K Kleinman, SL Rifas-Shiman, S Redline, EM Taveras (2014). Television viewing, bedroom television, and sleep duration from infancy to mid-childhood. Pediatrics, 133(5). Available 
at: http://pediatrics.aappublications.org/content/133/5/e1163 (accessed on $30 / 6 / 2019)$.

[52] Generación Z W Wikipedia. Available at: htps://es.wikipedia org/wiki/Generacion Z

[53] L Exelmans, J Van den Bulck (2016). Bedtime mobile phone use and sleep in adults. Soc Sci Med.,148:93-101.

[54] P McDougall, T Vaillancourt (2015). Long-term adult outcomes of pee victimization in childhood and adolescence: Pathways to adjustment and maladjustment. Am Psychol, 70(4), 300-310.

[55] T Vaillancourt, HL Brittain, P McDougall, E Duku (2013). Longitudinal links between childhood peer victimization, internalizing and externalizing problems, and academic functioning: developmental cascades. J Abnorm Child Psychol, 41(8), 1203-1215.

[56] S Livingstone \& EJ. Helsper (2008). Parental Mediation of Children's Internet Use, Journal of Broadcasting \& Electronic Media,52:4, 581-599.

[57] M Smahelova, D Juhová, I Cermak \& D Snahel (2017). Mediation of young children's digital technology use: The parents' perspective. Cyberpsychology: Journal of Psychosocial Research on Cyberspace, 11(3), article 4. http://dx.doi.org/10.5817/CP2017-3-4

[58] S Youn (2008). Parental influence and teens' attitude toward online privacy protection. Journal of Consumer Affairs, 42, 362388. http://dx.doi.org/10.1111/j.1745-6606.2008.00113.x

[59] W Shin (2018). Empowered parents: the role of self-efficacy in parental mediation of children's smartphone use in the United States. Journal of Children and Media, 12(4), 465-477.

[60] B Zaman, M Nouwen, J Vanattenhoven, E de Ferrerre, \& J Van Looy (2016). A qualitative inquiry into the contextualized parental mediation practices of young children's digital media use at home. Journal of Broadcasting \& Electronic Media, 60, 1-22. http://dx.doi.org/10.1080/08838151.2015.1127240.

[61] FA Graf, M Grumm, SD Hein, M Fingerle. Improving Parental Competencies: Subjectively Perceived Usefulness of a Parent Training Matters. Journal of Child and Family Studies 32(1).

[62] N Sonck, P Nikken \& J de Haan (2013). Determinants of Internet Mediation:, Journal of Children and Media, 7:1, 96-113.

[63] A Toffler 1970l. The Future Shock. Radom House.

[64] W Shin (2018). Empowered parents: the role of self-efficacy in parental mediation of children's smartphone use in the United States. Journal of Children and Media, 12(4), 465-477 